\title{
Reuso de água e efluente agroindustrial na produção de mudas de gravioleira
}

\section{Reuse of water and agroindustrial effluent in the production of soursop seedlings \\ Patrícia Roque Lemos Azevedo ${ }^{1 *}$, Ednaldo Barbosa Pereira Junior ${ }^{2}$, Joserlan Nonato Moreira ${ }^{2,}$ Diego Ernani Leite Bezerra ${ }^{3}$, Pedro Lima Filho ${ }^{4}$}

${ }^{1}$ Professora Mestre do Instituto Federal da Paraíba, Campus Sousa, Sousa, Paraíba, (83)3521 1224, patricia.roque@ifpb.edu.br; ${ }^{2}$ Professores Doutores do Instituto Federal da Paraíba, Campus Sousa, Sousa, Paraíba, ebpjr2@ hotmail.com, joserlan.moreira@ifpb.edu.br; ${ }^{3}$ Mestre do Instituto Federal da Paraíba, Campus Sousa, Sousa, Paraíba, diegobezerra82@hotmail.com; ${ }^{4}$ Doutorando em Agronomia, Universidade Federal da Paraíba, Campus Areia, Areia, Paraíba, pslimaf@yahoo.com.br

\section{A R T I G O}

Recebido: 27/04/2019

Aprovado: 18/09/2019

\section{Palavras-chave:}

Annona muricata L.

Solo

Reutilização

Key words:

Annona muricata L.

Soil

Reuse

\section{R E S U M O}

As condições climáticas do semiárido do Nordeste, caracterizadas pela irregularidade das chuvas, conferem à irrigação uma importância fundamental como instrumento que permite a viabilização de uma agricultura produtiva e estável. O presente estudo objetivou-se avaliar o desenvolvimento de mudas de gravioleira a partir do aproveitamento de água de ar condicionado e efluente agroindustrial. A pesquisa foi desenvolvida no setor de produção de mudas do Instituto Federal da Paraíba, Campus Sousa, Unidade São Gonçalo. Utilizou-se o delineamento de blocos inteiramente casualizados, com cinco tratamentos e quatro repetições. Os tratamentos resultaram das seguintes combinações: $\mathrm{T} 1=100 \%$ Poço Artesiano, T2 =100\% Ar Condicionado, T3 = Combinação 50\% Ar Condicionado + 50\% Poço Artesiano, T4 = Combinação 50\% Efluente Agroindustrial + 50\% Ar Condicionado e T5 $=100 \%$ Efluente Agroindustrial. As mudas de gravioleira foram produzidas em sacos de poliestireno, utilizando Neossolo Flúvico e esterco bovino na proporção (2:1) como substrato. Foram avaliadas as seguintes variáveis: altura de planta, diâmetro de caule, número de folhas, massa verde e seca da parte aérea e raiz e influência nos atributos do solo ( $\mathrm{pH}, \mathrm{P}, \mathrm{K}, \mathrm{Na}, \mathrm{Ca}, \mathrm{Mg}, \mathrm{MO}, \mathrm{PST}$ ). Verificou-se que a utilização de água de ar condicionado é uma alternativa viável como fonte de irrigação para as mudas de gravioleira, enquanto que o efluente agroindustrial não se mostrou adequada para este fim visto que influenciou negativamente na maioria das variáveis analisadas.

\section{A B S T R A C T}

The climatic conditions of the semiarid region of the northeast, characterized by the deficiency of rainfall, give irrigation a fundamental importance as one of the instruments to enable the viability of more agriculture Productive and with lower risk. Given the panorama of water scarcity, this paper aims to propose the development of soursop seedlings from the utilization of air conditioning and agroindustrial effluent. The research was developed in the seedling production sector located at the Federal Institute of Paraíba, Campus Sousa. A completely randomized block design was used, with five treatments and four replications. The treatments resulted from the following combinations: $\mathrm{T} 1=100 \%$ Artesian Well, $\mathrm{T} 2=$ $100 \%$ air conditioning, T3 = combination 50\% air conditioning $+50 \%$ Artesian Well, T4 = combination 50\% agroindustrial effluent $+50 \%$ air conditioning and $\mathrm{T} 5=100 \%$ agroindustrial effluent. Soursop seedlings were produced in plastic bags using Neossol Fluvic and manure in proportion $(2: 1)$ as substrate. The following variables were evaluated: plant height, stem diameter, number of leaves, green and dry mass of aerial part and root and influence on soil attributes (PH, P, K, Na, Ca, Mg, MO, PST). After the study, it was verified that the use of air-conditioning water is a good alternative as a source of irrigation for the seedlings of Gravioleira, while the water of agroindustrial effluent was not adequate for this purpose, since it influenced Negatively in most of the variables analyzed.

\section{INTRODUÇÃO}

A cultura da gravioleira (Annona muricata L.) tem se destacado por apresentar potencial favorável de comercialização no mercado interno e com perspectivas para exportação. Por ser uma espécie cultivada em países subtropicais e tropicais, revela viabilidade econômica de cultivo na região Nordeste, em função das condições edafoclimáticas compatíveis com suas exigências nutricionais e fisiológicas (BARBOSA, 2003). A crescente demanda de seus frutos para consumo in natura e processamento da polpa 
tem impulsionado a expansão da área cultivada evidenciando a cultura como alternativa de investimento do setor frutícola nordestino, inserindo-a como umas das frutíferas de grande valor comercial.

Diante do panorama de escassez hídrica e da observação do funcionamento de um sistema de ar condicionado e da produção de efluentes agroindustriais, cogitou-se a possibilidade de utilizar a água condensada fornecida pelos aparelhos de ar condicionado e de efluente agroindustrial na irrigação de mudas de graviola, frutífera de alto valor econômico bastante utilizada em polpas, sucos e néctares. Assim, seria possível verificar a viabilidade de produção de mudas de graviola usando, como insumo de irrigação, águas que são descartadas e sem finalidade específica, bem como analisar as possíveis influências nas características morfológicas da planta.

A utilização de métodos alternativos de reutilização da água, como o aproveitamento das águas pluviais, água-cinza, águas residuais tratadas e a dessalinização, que aparecem como meios de conservação da água e como alternativas para enfrentar a falta desse recurso, tanto para fins potáveis quanto não potáveis, tornando uma opção prática e a baixo custo para minimizar a escassez (PUSHARD, 2008). Assim, o aproveitamento de águas como fonte de irrigação para o desenvolvimento de culturas economicamente viáveis favorece melhorias de vida de uma determinada localidade.

Os aparelhos de ar condicionado promovem a geração de água líquida resultante do processo de condensação. Essa água, na maioria das vezes, é desperdiçada para o solo ou para o esgoto, não tendo, portanto, um aproveitamento. De acordo com Mota (2012) em média um aparelho de ar condicionado com 12 mil BTUs gera em torno de $300 \mathrm{~mL}$ de água por hora, desta forma, se pegarmos um escritório que fica em média 12 horas com o ar ligado das 7 h às 19 h serão 3,6 litros de água produzidos por este aparelho, sem restrição quanto classificação devido as baixas concentrações de sais e sódio (C1S1) para irrigação, conforme Pereira Junior et. al (2017).

Nóbrega et al. (2018) afirma que a água de ar condicionado se mostrou uma alternativa viável para a utilização na irrigação de mudas de goiaba, evidenciando menores resultados para altura de plantas e número de folhas irrigado com efluente agroindustrial. Kummer et al. (2012) afirmam que a utilização de efluentes na agricultura cresceu consideravelmente nos últimos anos em muitos países, inclusive no Brasil. No entanto, ainda não foram suficientemente estudados todos os aspectos positivos e negativos dessa técnica, especialmente sobre as propriedades físicas e químicas do solo, absorção de nutrientes pelas plantas ou sua toxicidade.

Diante do exposto, com o presente estudo objetivou-se avaliar o desenvolvimento de mudas de gravioleira a partir do aproveitamento de água de ar condicionado e efluente agroindustrial e sua influência nos atributos do solo.

\section{MATERIAL E MÉTODOS}

O experimento foi desenvolvido no viveiro de mudas do Instituto Federal de Educação, Ciência e Tecnologia da
Paraíba (IFPB) Campus Sousa, unidade São Gonçalo, durante o período de setembro de 2017 a janeiro de 2018.

Durante o período do experimental as condições climáticas do Perímetro Irrigado de São Gonçalo são caracterizadas por precipitação pluvial média de $21,8 \mathrm{~mm}$, temperatura média de $28,4^{\circ} \mathrm{C}$, o que provocou uma taxa de evaporação média de $243,35 \mathrm{~mm}$. Conforme a classificação de Köppen, o clima da região é do tipo BSh, o que indica um clima semiárido quente, marcado por taxas de evapotranspiração potencial anual superior à precipitação anual e a inexistência de cursos de água permanentes (BRASIL, 2018; BRASIL, 2019).

Para o desenvolvimento das mudas, as sementes foram irrigadas águas provenientes de ar condicionado, efluente agroindustrial e água de poço. A água de ar condicionado foi coletada por meio de sistema de captação constituído por tubos de PVC de $20 \mathrm{~mm}$ conectados na saída de cada mangueira de dreno dos aparelhos e direcionados para uma caixa coletora de 500 litros, localizada no bloco predial do curso de Agroecologia, sendo este formado por 16 dependências climatizadas com sistema de ar condicionado que variam na faixa de 12.000 a 24.000 BTUS, sendo sete ligados diariamente durante o horário de expediente (PEREIRA JÚNIOR et al., 2017). O efluente agroindustrial foi direcionado mediante a um desvio feito na tubulação do esgoto do Setor de Processamento de Leite e Derivados e armazenado em reservatório coletor de capacidade de 500 litros, localizada no Bloco da Agroindústria (FERREIRA NETO et al., 2017). E por fim, a água de poço foi coletada em um poço artesiano localizado próximo ao Bloco de Agroindústria.

O delineamento experimental foi realizado utilizando-se de blocos inteiramente casualizados, com cinco (05) tratamentos e cinco (05) repetições. A parcela experimental foi composta por cinco (05), plantas e os tratamentos resultantes foram os seguintes: Água do poço artesiano (PA); Água dos sistemas de ar condicionado (AC); Combinação (50\% de AC + 50\% de PA); Combinação (50\% de AC + 50\% de EA); Efluente agroindustrial (EA).

Foram utilizadas sementes de graviola, cultivar Morada, oriundas de feiras e/ou supermercados do município de Sousa-PB como materiais propagadores. Essas sementes foram retiradas manualmente de frutos sadios e maduros, em seguida foram lavadas a fim de retirar todo resquício de polpa $\mathrm{e}$, posteriormente, foram mantidas à sombra em local arejado para secagem durante uma semana. É importante frisar que não foi efetuado nenhum tratamento prévio que pudesse facilitar seu processo germinativo.

O substrato foi preparado misturando-se manualmente o solo e esterco bovino na proporção 2:1 v/v. Após a homogeneização do substrato, sacos de poliestireno de capacidade de 2 litros foram preenchidos e encaminhados ao viveiro de mudas. Em seguida, foi separada uma amostra do substrato para a realização da análise química feita no Laboratório de Análises de Solo, Água e Planta (LASAP), do IFPB Campus Sousa - PB, conforme Tabela 1.

Tabela 1. Análise química do substrato preparado para o experimento, Instituto Federal de Educação, Ciência e Tecnologia da Paraíba, Campus Sousa.

\begin{tabular}{cccccccccccc}
\hline $\mathrm{pH}$ & $\mathrm{P}$ & $\mathrm{K}$ & $\mathrm{Na}$ & $\mathrm{Ca}$ & $\mathrm{Mg}$ & $\mathrm{Al}$ & $\mathrm{H}+\mathrm{Al}$ & $\mathrm{SB}$ & $\mathrm{CTC}$ & $\mathrm{MO}$ & $\mathrm{PST}$ \\
\hline $\mathrm{H}_{2} \mathrm{O}$ & $\mathrm{mg} \mathrm{dm}^{-3}$ & ------------------------------- & \multicolumn{2}{c}{$\mathrm{Cmol}^{\mathrm{c}} \mathrm{dm}^{-3}$} & ----------------------- & $\mathrm{g} \mathrm{kg}^{-1}$ & $\%$ \\
\hline 7,6 & 1196 & 3,40 & 0,86 & 7,6 & 0,5 & 0,00 & 0,00 & 12,36 & 12,36 & 24,29 & 7 \\
\hline
\end{tabular}


A semeadura foi realizada colocando-se três sementes, em uma profundidade média de $2,0 \mathrm{~cm}$ em cada recipiente e recobrindo-as com uma fina camada de substrato, totalizando, assim, 100 recipientes distribuídos em um ambiente protegido conforme os tratamentos utilizados na pesquisa. A irrigação foi efetuada diariamente, fornecendo de água suficiente para manter a umidade do substrato próximo à capacidade de campo. Durante o período de condução do experimento, não foi feita nenhuma adubação em cobertura. O desbaste foi realizado manualmente com o auxílio de uma tesoura após 90 dias após a semeadura (DAS).

Durante o período experimental foram coletadas amostras de águas em três fases distintas para serem analisadas: a primeira no início, a segunda após 45 DAS e a terceira com 90 DAS que corresponde ao fim do experimento e encaminhadas para o LASAP, do IFPB, Campus Sousa (Tabela 2).

Tabela 1. Análise química das águas de irrigação (valores médios). Instituto Federal de Educação, Ciência e Tecnologia da Paraíba, Campus Sousa.

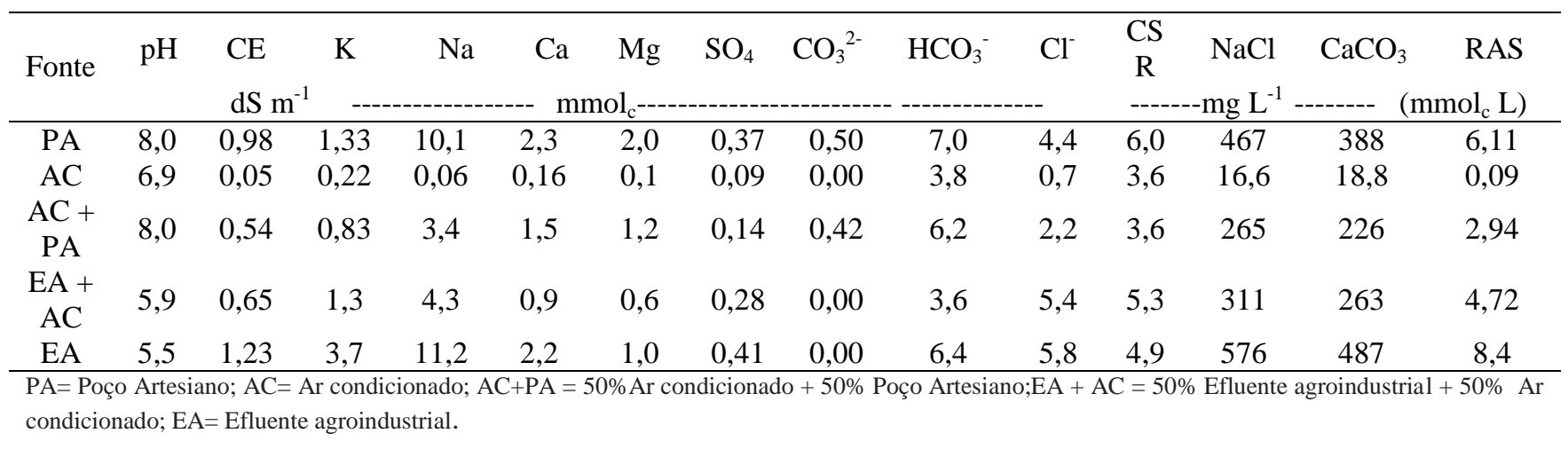

As características morfológicas altura de planta - AP (obtido pela distância entre a região do colo e a gema apical do ramo principal), diâmetro do caule - DC (obtido pela medição das plantas a dois centímetros acima do colo, com o auxílio de um paquímetro digital) e número de folhas - NF (obtido pela contagem total do número de folhas totalmente expandidas) foram mensurados aos 30, 60 e 90 (DAS).

Após os 90 (DAS) foram determinadas as variáveis: massa fresca da parte aérea (MFPA), massa fresca da raiz (MFR), massa seca da parte aérea (MSPA) e da raiz (MSR), esta última obtida pela separação da raiz através de um corte na região do colo, posteriormente acondicionadas em sacos de papel, devidamente etiquetadas e secadas em estufa a $65^{\circ} \mathrm{C}$, com circulação forçada de ar até peso constante.

Analise química do solo: Ao final do experimento foram coletados ainda amostras de solo em cada parcela experimental para determinação do $\mathrm{pH}$ e os teores de fósforo $(\mathrm{P})$, potássio $(\mathrm{K})$, sódio $(\mathrm{Na})$, cálcio $(\mathrm{Ca})$, magnésio $(\mathrm{Mg})$, matéria orgânica (MO) e porcentagem de sódio trocável (PST) com o objetivo de verificar possíveis mudanças nas características do solo durante o período experimental, analisada conforme a metodologia da EMBRAPA (1997) no LASAP do IFPB, Campus Sousa.

Os resultados foram submetidos à Análise de Variância (ANOVA) e as médias, comparadas pelo teste de Tukey, a 5\% de probabilidade, através do programa SISVAR (FERREIRA, 2011).

\section{RESULTADOS E DISCUSSÃO}

A análise dos resultados no desenvolvimento das mudas de gravioleira apresenta valores significativos $(\mathrm{p}<0,05)$ para as variáveis, altura de planta (AP) aos 30 e 60 (DAS), diâmetro do caule (DC) em 30 (DAS), massa fresca (raiz) e massa seca (raiz) em 90 (DAS). O número de folhas (NF), Massa fresca da parte aérea (MFPA) e Massa seca da pare aérea (MSPA) apresentaram resultados significativos.
A altura de planta (AP) apresentou efeitos significativos nos tratamentos T1 e T3 nos 30 (DAS).. Entretando, constatou que o T2 inferiu incremento na AP de $37 \%$ de 60 para 90 (DAS) nos períodos coletados (tabela 3). Percebe-se que os tratamentos com menores Condutividades elétrica (CE) propiciaram melhores resultados e com aumento da salinidade da água um decréscimo (tabela 2). Resultados obtidos por Cavalcante et al. (2001) com uso de água salina de até $10,0 \mathrm{dS}$ m-1 constatou a redução no crescimento das plantas de gravioleira em razão do estresse salino.

Ao comparar esses resultados com outros obtidos em mamoeiro (BEZERRA et al., 2019), cajueiro (PEREIRA JUNIOR et al., 2018) e maracujazeiro (LIMA et al., 2019), constatou-se resultados expressivos irrigados com água dos sistema de ar condicionados, por outro lado, redução a medida que foram aumentando a salinidade promovido pelo efluente agroindustrial.

Tabela 3. Altura das mudas de graviola, irrigadas com diferentes tipos de água.

\begin{tabular}{cccc}
\hline \multicolumn{4}{c}{ Após aplicação dos tratamentos } \\
Tratamentos & 30 dias & 60 dias & 90 dias \\
\hline T1 & $13,03 \mathrm{a}$ & $16,49 \mathrm{~b}$ & $20,91 \mathrm{c}$ \\
T2 & $10,50 \mathrm{bc}$ & $18,82 \mathrm{a}$ & $25,70 \mathrm{a}$ \\
T3 & $12,05 \mathrm{ab}$ & $16,28 \mathrm{~b}$ & $22,89 \mathrm{~b}$ \\
T4 & $10,39 \mathrm{bc}$ & $14,80 \mathrm{c}$ & $20,34 \mathrm{c}$ \\
T5 & $9,98 \mathrm{c}$ & $14,18 \mathrm{c}$ & $20,61 \mathrm{c}$ \\
\hline CV \% & 8,11 & 3,97 & 9,19
\end{tabular}

T1= Poço Artesiano; T2 = Ar condicionado; T3 = 50\% Ar condicionado + $50 \%$ Poço Artesiano; T4 $=50 \%$ Efluente agroindustrial $+50 \% \mathrm{Ar}$ condicionado; T5= Efluente agroindustrial. Médias seguidas, em coluna, com letras diferentes apresentaram efeitos significativo a nível de $(\mathrm{p}<0,05)$ pelo teste Tukey.

Em trabalho com mudas de goiabeira irrigadas com diferentes tipos de águas, Nóbrega et al. (2017) constataram maiores alturas para as mudas que foram irrigadas com água de ar condicionado. 
Nos tratamentos T1, T4 e T5 aos 90 (DAS) na tabela 3 constatou-se as menores alturas, cujos efeitos podem estar relacionados à salinidade em virtude da deposição de sais no substrato, o que provocou uma diminuição do potencial osmótico da solução do solo, acarretando, assim, um atraso no período de embebição das sementes e, consequentemente, o desenvolvimento das plântulas (NOBRE et al., 2003).

Não se observou diferença significativa para o diâmetro do caule aos 60 e 90 (DAS). Aos 30 (DAS) o tratamento T1 evidenciou resultado superior, porém não diferindo estatisticamente dos tratamentos T2 e T3 (tabela 4), enquanto que a menor média foi obtido pelo T5 irrigado com efluente agroindustrial.

Tabela 4. Diâmetros do caule das mudas de graviola, irrigadas com diferentes tipos de água.

\begin{tabular}{cccc}
\hline \multicolumn{4}{c}{ Após aplicação dos tratamentos } \\
Tratamentos & 30 dias & 60 dias & 90 dias \\
\hline T1 & $2,02 \mathrm{a}$ & $2,33 \mathrm{a}$ & $2,65 \mathrm{a}$ \\
T2 & $1,73 \mathrm{ab}$ & $2,41 \mathrm{a}$ & $2,82 \mathrm{a}$ \\
T3 & $1,92 \mathrm{ab}$ & $2,23 \mathrm{a}$ & $2,88 \mathrm{a}$ \\
T4 & $1,65 \mathrm{bc}$ & $2,08 \mathrm{a}$ & $2,39 \mathrm{a}$ \\
T5 & $1,52 \mathrm{c}$ & $1,83 \mathrm{a}$ & $2,36 \mathrm{a}$ \\
\hline CV \% & 8,33 & 16,94 & 15,43 \\
\hline
\end{tabular}

$\mathrm{T} 1=$ Poço Artesiano; $\mathrm{T} 2=\mathrm{Ar}$ condicionado; $\mathrm{T} 3=50 \% \mathrm{Ar}$ condicionado + $50 \%$ Poço Artesiano; T4 $=50 \%$ Efluente agroindustrial $+50 \% \mathrm{Ar}$ condicionado; T5= Efluente agroindustrial. Médias seguidas, em coluna, com letras diferentes apresentaram efeitos significativo a nível de $(\mathrm{p}<0,050)$ pelo teste Tukey.

O aumento da quantidade de sais depositados nos substratos pelas águas de irrigação afeta consideravelmente o desenvolvimento morfológico das mudas, tanto que se observaram os menores diâmetros no T5, aonde se tem os maiores teores de sais, principalmente o sódio, e CE média de $1,23 \mathrm{dS} . \mathrm{m}^{-1}$ (vide Tabela 2). Resultado semelhante foi encontrado por Nobre et al. (2003) em seu trabalho com a germinação e formação de mudas enxertadas de gravioleira sob estresse salino. Os autores atribuíram seus resultados ao aumento da salinidade nas águas de irrigação.

Quanto ao número de folhas (NF), os maiores valores foram observados no T2 aos 60 (DAS), a mesma tendência foi seguida aos 90 (DAS), indicando que águas de irrigação com baixos teores de sais promovem um maior e melhor desenvolvimento das folhas.

Comparando os parâmetros morfológicos AP, DC e NF, verificou-se que este último foi o mais afetado pelo efeito da salinidade, pois Kyoro (2000) afirma que a redução do tamanho e do número de folhas indica que a frutífera está sob um elevado nível de estresse salino.

Tabela 5. Número de folhas de mudas de graviola, irrigadas com diferentes tipos de água.

\begin{tabular}{cccc}
\hline \multicolumn{4}{c}{ Após aplicação dos tratamentos } \\
Tratamentos & 30 dias & 60 dias & 90 dias \\
\hline T1 & $5,13 \mathrm{a}$ & $8,25 \mathrm{bc}$ & $11,82 \mathrm{c}$ \\
T2 & $4,13 \mathrm{a}$ & $9,97 \mathrm{a}$ & $14,65 \mathrm{a}$ \\
T3 & $4,95 \mathrm{a}$ & $8,21 \mathrm{bc}$ & $12,93 \mathrm{bc}$ \\
T4 & $4,10 \mathrm{a}$ & $7,46 \mathrm{c}$ & $11,83 \mathrm{c}$ \\
T5 & $3,80 \mathrm{a}$ & $7,67 \mathrm{c}$ & $12,54 \mathrm{c}$ \\
\hline CV \% & 14,15 & 10,45 & 6,24 \\
\hline
\end{tabular}

T1= Poço Artesiano; $\mathrm{T} 2=$ Ar condicionado; $\mathrm{T} 3=50 \%$ Ar condicionado + $50 \%$ Poço Artesiano; $\mathrm{T} 4=50 \%$ Efluente agroindustrial $+50 \% \mathrm{Ar}$ condicionado; T5= Efluente agroindustrial. Médias seguidas, em coluna, com letras diferentes apresentaram efeitos significativo a nível de $(\mathrm{p}<0,050)$ pelo teste Tukey.
Os resultados obtidos para a massa fresca da parte área (MFPA), massa fresca da raiz (MFR), massa seca da parte aérea (MSPA) e massa seda da raiz (MSR) apresentaram diferença significativos entre os tratamentos (tabela 6), verifica-se que as maiores médias foram registradas pelos tratamentos T2 e T3, provavelmente os baixos teores salinos dos tratamentos utilizadas pra irrigação (tabela 2) colaboraram para esse comportamento, exceto para o tratamento T1, que apesar dos teores salinos elevados, demonstrou mais eficiente para massa fresca da raiz $(14,76 \mathrm{~g})$ e massa seca da raiz (11,32 g). É importante destacar que, os menores valores ocorreram quando irrigados pelos os tratamentos T4 e T5. Estes resultados mostram o quanto salinidade do efluente agroindustrial interfere negativamente no desenvolvimento dos órgãos de absorção de água e nutrientes das mudas de gravioleira, em especial as raízes.

Tabela 6. Massa fresca e seca da parte aérea e raiz de mudas de gravioleira, aos 90 dias irrigados com diferentes tipos de água.

\begin{tabular}{ccccc}
\hline \multirow{2}{*}{ Tratamentos } & \multicolumn{2}{c}{ Massa da Fresca } & \multicolumn{2}{c}{ Massa Seca } \\
& Aérea & Raiz & Aérea & Raiz \\
\hline T1 & $18,88 \mathrm{a}$ & $14,76 \mathrm{a}$ & $12,44 \mathrm{~b}$ & $11,32 \mathrm{a}$ \\
T2 & $18,51 \mathrm{~b}$ & $11,56 \mathrm{~b}$ & $12,72 \mathrm{a}$ & $8,55 \mathrm{~b}$ \\
T3 & $18,48 \mathrm{bc}$ & $11,98 \mathrm{~b}$ & $12,04 \mathrm{~b}$ & $8,99 \mathrm{~b}$ \\
T4 & $18,65 \mathrm{~b}$ & $8,80 \mathrm{c}$ & $11,48 \mathrm{c}$ & $5,99 \mathrm{c}$ \\
T5 & $16,62 \mathrm{c}$ & $7,98 \mathrm{c}$ & $10,63 \mathrm{c}$ & $6,19 \mathrm{c}$ \\
\hline CV \% & 4,55 & 6,93 & 4,08 & 13,23 \\
\hline
\end{tabular}

$\mathrm{T} 1=$ Poço Artesiano; $\mathrm{T} 2=\mathrm{Ar}$ condicionado $; \mathrm{T} 3=50 \% \mathrm{Ar}$ condicionado + $50 \%$ Poço Artesiano; $\mathrm{T} 4=50 \%$ Efluente agroindustrial $+50 \% \mathrm{Ar}$ condicionado; T5= Efluente agroindustrial. Médias seguidas, em coluna, com letras diferentes apresentaram efeitos significativo a nível de $(\mathrm{p}<0,05)$ pelo teste Tukey.

Estes resultados divergem dos encontrados por Cavalcante et al (2001) que afirmam que águas de irrigação com uma CE de até 2,0 dS.m ${ }^{-1}$ promovem efeitos positivos tanto na MFPA, como também na MFR no desenvolvimento inicial de mudas de gravioleira.

Em relação à massa seca, verificou diferenças significativas para a parte aérea, porém na parte radicular, observou-se significância para os tratamentos T1, T2 e T3, com destaque para o tratamento T1 (água de poço artesiano). Resultado semelhante foi encontrado por Neto et al. (2017) ao avaliar a MFR do feijão guandu e da soja irrigados com água de poço artesiano e de ar condicionado. Os autores atribuem esse comportamento ao estresse salino que faz com que plantas alonguem suas raízes em busca de mais nutrientes. As mudas irrigadas com os T4 e T5 apresentaram os menores resultados, que podem ser atribuídos à má qualidade do efluente agroindustrial.

É importante frisar alterações no equilíbrio nutricional e fisiológicos provocados pelo estresse salino podem influenciar diretamente na conversão de carbono assimilado pelas plantas, promovendo, assim, reduções no crescimento e na biomassa das culturas (TAIZ; ZEIGER, 2013).

Conforme a análise de variância houve diferença significativa $(\mathrm{p}<0,05)$ para o $\mathrm{pH}$ do solo, embora demonstrem significância pelo fato de o pH permanecer alcalino (tabela 7). Comparando os tratamentos, o $\mathrm{T} 1$ elevou o $\mathrm{pH}$ do solo, enquanto que o T5 apresentou o menor valor, entretanto o aumento de $\mathrm{pH}$ em todos os tratamentos pode ser atribuído à concentração de sódio presente nas águas de irrigação. Segundo Pinto e Silva (1997), a gravioleira, por ser a mais 
tropical de todas as anonáceas, é pouco exigente em relação ao fator fertilidade, embora requeira solos ricos em material orgânico e com o pH ligeiramente ácido em torno de 6,0 a
6,5. Diante do exposto, a alcalinidade do substrato pode ter influenciado de maneira negativa e significativa no desenvolvimento das mudas de graviola.

Tabela 7. Características químicas do solo após o término do experimento, irrigados com diferentes tipos de águas

\begin{tabular}{|c|c|c|c|c|c|c|}
\hline \multirow{2}{*}{$\begin{array}{l}\text { Características químicas } \\
\text { (fertilidade do solo) }\end{array}$} & \multicolumn{5}{|c|}{ Tratamentos } & \multirow[b]{2}{*}{$\mathrm{CV}(\%)$} \\
\hline & $\mathrm{T} 1$ & $\mathrm{~T} 2$ & $\mathrm{~T} 3$ & $\mathrm{~T} 4$ & T5 & \\
\hline $\mathrm{pH}$ & $8,60 \mathrm{~b}$ & $8,40 \mathrm{bc}$ & $8,38 \mathrm{bc}$ & $8,38 \mathrm{bc}$ & $8,28 \mathrm{c}$ & 1,34 \\
\hline Fósforo (mg dm $\left.{ }^{-3}\right)$ & $1,37 \mathrm{a}$ & $1,45 \mathrm{a}$ & $1,42 \mathrm{a}$ & $1,33 \mathrm{a}$ & $1,40 \mathrm{a}$ & 6,25 \\
\hline Potássio $\left(\mathrm{cmol}_{\mathrm{c}} \mathrm{dm}^{-3}\right)$ & $2,46 \mathrm{~b}$ & $2,65 \mathrm{~b}$ & $2,66 \mathrm{~b}$ & $2,27 \mathrm{~b}$ & $1,60 \mathrm{c}$ & 9,23 \\
\hline Sódio $\left(\mathrm{cmol}_{\mathrm{c}} \mathrm{dm}^{-3}\right)$ & $1,61 \mathrm{a}$ & $0,47 \mathrm{c}$ & $1,05 \mathrm{~b}$ & $1,31 \mathrm{a}$ & $1,35 \mathrm{a}$ & 7,02 \\
\hline Cálcio $\left(\mathrm{cmol}_{\mathrm{c}} \mathrm{dm}^{-3}\right)$ & $6,00 \mathrm{a}$ & $6,75 \mathrm{a}$ & $6,65 \mathrm{a}$ & $6,05 \mathrm{a}$ & $7,05 \mathrm{a}$ & 8,02 \\
\hline Magnésio $\left(\mathrm{cmol}_{\mathrm{c}} \mathrm{dm}^{-3}\right)$ & $1,53 \mathrm{c}$ & $1,45 \mathrm{c}$ & $1,40 \mathrm{c}$ & $1,80 \mathrm{~b}$ & $2,05 \mathrm{~b}$ & 6,75 \\
\hline Material Orgânico $\left(\mathrm{g} \mathrm{kg}^{-1}\right)$ & $33,95 \mathrm{ab}$ & $35,57 \mathrm{a}$ & $30,88 \mathrm{c}$ & $33,24 \mathrm{abc}$ & $31,65 \mathrm{bc}$ & 3,83 \\
\hline PST \% & $13,75 \mathrm{a}$ & $3,75 \mathrm{c}$ & $8,75 \mathrm{~b}$ & $11,50 \mathrm{a}$ & $11,00 \mathrm{a}$ & 8,11 \\
\hline
\end{tabular}

T1= Poço Artesiano; T2= Ar condicionado; T3 = 50\% Ar condicionado + 50\% Poço Artesiano; T4 = 50\% Efluente agroindustrial + 50\% Ar condicionado; T5= Efluente agroindustrial. Médias seguidas, em linha, com letras diferentes apresentaram efeitos significativo a nível de $(\mathrm{p}<0,05)$ pelo teste Tukey.

As concentrações de $\mathrm{P}, \mathrm{Mg}^{+2}$ e $\mathrm{Ca}^{+2}$ no solo não demonstraram diferenças significativas entre os tratamentos, embora a concentração do $\mathrm{P}$ tenha permanecido baixa, enquanto que as do $\mathrm{Ca}^{+2}$ e, principalmente, $\mathrm{Mg}^{+2}$ tenham se elevado. Esperava-se que os solos irrigados com os tratamentos T1 e T5 deveriam expressar maiores teores de cálcio e magnésio e menor no $\mathrm{T} 2$, entretanto não foi o que ocorreu (Tabelas 2,3 e 4).

Em cultivos irrigados com água de boa qualidade, Penteado (2004) afirma que o cálcio tem mais importância como nutriente na agricultura orgânica; o mesmo autor considera como níveis adequados no solo a relação entre $\mathrm{Ca}^{2+}$ e $\mathrm{Mg}^{2+}$ de 3:1. Entretanto, de acordo com Garcia et al. (2008), a importância das relações entre os cátions trocáveis, como

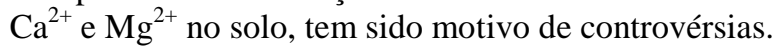

Em relação aos teores de $\mathrm{K}^{+}$no solo, houve diferença significativa $(\mathrm{p}<0,05)$. Os tratamentos $\mathrm{T} 1, \mathrm{~T} 2, \mathrm{~T} 3$ e T4 apresentaram maiores concentrações de $\mathrm{K}^{+}$em relação ao T5, conforme mostrado na Tabela 9. É importante ressaltar que o valor médio do teor de $\mathrm{K}^{+}$nos quatro tratamentos supracitados corresponde a $73,82 \%$ do teor inicial do substrato (Tabela 1).

Os teores de $\mathrm{Na}^{+}$apresentaram diferenças significativas nos tratamentos T1, T3 e T5 que apontaram maiores valores quando comparandos os T2 e T3. Segundo Freitas et al. (2012), quando o pH, a condutividade elétrica e a sodicidade da água de irrigação se encontram em condições prejudiciais às espécies vegetais, poderá haver uma queda no desempenho da cultura.

A percentagem de sódio trocável (PST) no solo pode ser elevada dependendo da quantidade de sódio presente na água de irrigação, o que acarretará dificuldades de a água ser utilizada pela planta. (SOUSA et al., 2008). Fato este observado no tratamento T1, cujo maior teor de sódio $(1,61$ $\left.\mathrm{cmol}_{\mathrm{c}} \mathrm{dm}^{-3}\right)$ é também aonde se verifica a maior PST. Vale ressaltar que, segundo a classificação, o solo do T2 é o único que se encontra dentro da faixa $(0-7 \%)$ que não trará maiores problemas para o cultivo de maiores culturas.

O teor da matéria orgânica (MO) é um parâmetro que avalia indiretamente a disponibilidade de nitrogênio no solo, macronutriente fundamental para o desenvolvimento das plantas (PES; ARENHARDT, 2015). Os tratamentos T1 e T2 apresentaram resultados significativos $(\mathrm{p}<0,05)$ em relação aos demais tratamentos. Porém, segundo a classificação dos solos em relação ao teor de $\mathrm{MO}$, todos os tratamentos são classificados como teor de MO médio (2,6 - 5,0\%) (BRASIL, 2004), conforme mostrado na Tabela 7. Como a gravioleira é uma frutífera que requer solos ricos em matéria orgânica para se desenvolver (PINTO; SILVA, 1995), então se tem os tratamentos $\mathrm{T} 1$ e $\mathrm{T} 2$ como meio mais propício ao desenvolvimento de mudas.

Segundo Sá (2015), o aumento da matéria orgânica promove melhorias na estrutura do solo, bem como nos processos de floculação e formação de agregados, garantindo uma melhoria na infiltração da água de irrigação, o que pode reduzir os índices de salinidade. Estes resultados foram encontrados por Sousa et al (2008) ao avaliar os substratos e biofertilizantes na produção de mudas de maracujazeiro amarelo sob irrigação com água salina.

\section{CONCLUSÕES}

A água de ar condicionado é indicada para a produção de mudas de gravioleira.

$\mathrm{O}$ efluente agroindustrial afeta de forma negativa o crescimento de mudas de gravioleira em virtude dos elevados teores de sódio e cloreto.

\section{REFERÊNCIAS}

BARBOSA, Z.; SOARES, I.; CRISÓSTOMO, L. A. Crescimento e absorção de nutrientes por mudas de gravioleira. Revista Brasileira de Fruticultura, v.25, n.3, p.519-522, 2003. 10.1590/S0100-29452003000300039.

BRASIL. Instituto Brasileiro de Geografia e Estatística. Cadastro de Municípios localizados na Região Semiárida do Brasil. Disponível em: <https://ww2.ibge.gov.br/home/geociencias/geografia/semiari do.shtm> Acesso em: 25/07/2018

BRASIL. Instituto Nacional de Meteorologia. Estação do Perímetro Irrigado de São Gonçalo/Sousa - PB. Mapa de Observações Meteorológicas. Outubro/2017 a Janeiro/2018. Disponível em: <http://www.inmet.gov.br/portal/index.php?r=estacoes/estaco esAutomaticas>. Acesso em:31/01/2019

BRASIL, Sociedade Brasileira de Ciência do Solo. Comissão de Química e Fertilidade do Solo. Manual de adubação e de calagem para os Estados do Rio Grande do Sul e de Santa Catarina. 10. ed.- Porto Alegre, 2004. 
CAVAlCANTE, L. F.; CARVALHO, S. S.; LIMA, E. M.; FEITOSA FILHO, J. C.; SILVA, D. A. Desenvolvimento inicial da gravioleira sob fontes e níveis de salinidade da água. Revista Brasileira de Fruticultura. v. 23, n. 2, p. 455459, 2001.

FERREIRA, D. F. SISVAR: Um sistema computacional de análise estatística. Revista Ciência e Agrotecnologia. v. 35, n. 6, p. 1039-1042, 2011.

FERREIRA NETO, J.; DE QUEIRÓS M. M. F., NOBRE, R. G., PEREIRA JUNIOR, E. B., SOUSA, J. C.; SOUSA, J. X. Caracterização físico-química e microbiológica da beterraba irrigada com efluente agroindustrial. Revista de Agroecologia no Semiárido, v. 1, n.1, p.13 - 23, 2017.

FREITAS, C. A. S.; SILVA, A. R. A.; BEZERRA, F. M. L.; ANDRADE, R. R.; MOTA, F. S. B.; AQUINO, B. F. Crescimento da cultura do girassol irrigado com diferentes tipos de água e adubação nitrogenada. Revista Brasileira de Engenharia Agrícola e Ambiental. v. 16, n. 10, p.1031-1039, 2012.

GARCIA, G. O.; MARTINS FILHO, S.; REIS, E. F.; MORAES, W. B.; NAZÁRIO, A. A. Alterações químicas de dois solos irrigados com água salina. Revista Ciência Agronômica, v. 39, n. 1, p. 7-18, 2008.

GOMES, J. DE L.; BARBINIERI, José Carlos. Gerenciamento de recursos hídricos no Brasil e no estado de São Paulo: um novo modelo de política pública. Cad. EBAPE.BR. v. 2, n. 3, p.01-21, 2004.

KOYRO, H. M. Effect of high NaCl-salinity on plant growth, leaf morphology, and ion composition in leaf tissues of Beta vulgaris ssp. maritime. Journal of Applied Botany, v. 74, n. $1 / 2$, p. $67-73,2000$.

LIMA, F. V. S.; CASIMIRO, D. E.; PEREIRA JUNIOR, E. B.; SILVA, P.S.; CASSIMIRO, C. A. L. Análise morfológica de mudas de maracujazeiro irrigadas com diferentes tipos de água. Rev.Bras.de Gestão Ambiental (Pombal, PB), v.13, n.02,01-06, 2019. https://doi.org/10.18378/rbga.v13i2.6126

MOTA, T. R.; OLIVEIRA, D. M.; INADA, P. Utilização da água do sistema de ar condicionado visando o desenvolvimento sustentável. $10^{\circ}$ Fórum de Extensão e cultura da UEM, 2012.

NETO, N. D.; CRUZ, ELISAMA M. O.; ALENCAR, D. C.S.N.; SILVA, E. A. Análise fisiológica de fabaceae sob diferentes tipos de água. Revista Agroecologia no Semiárido. v.1, n.2, p.7-14, 2017

NOBRE, R. G.; FERNANDES, Pedro D.; GHEVI, Hans R.; SANTOS, Francisco J. S.; BEZERRA, Idelfonso L.; GURGEL, Marcelo T. Germinação e formação de mudas enxertadas de gravioleira sob estresse salino. Revista Pesquisa Agropecuária Brasileira. v. 38, n. 12, p. 1365-1371, 2003.

NÓBREGA, E. P.; SARMENTO, M. I. A.; RODRIGUES, M. L. M.; OLIVEIRA, P. R. R.; NETO, J. F.; MARACAJÁ, P.
Desenvolvimento inicial de mudas de goiabeira irrigadas com diferentes tipos de água. Revista de Agroecologia no Semiárido, v. 1, n. 2, p. 01-09, 2018.

PENTEADO, S. R. Fruticultura orgânica: formação e condução. Viçosa: Aprenda Fácil, 2004. 308 p.

PEREIRA JUNIOR, E. B.; SOUSA, J. F.; LIMA, C. J.; HAFLE, O. M.; GOMES, D. J.; OLIVEIRA, F. T. Quantidade e qualidade da água dos aparelhos condicionadores de ar no IFPB-Campus Sousa, PB. Revista de Agroecologia no Semiárido, v. 1, n. 1, p. 1-12, 2017.

PEREIA JUNIOR, B.; SOUSA, P.; CASIMIRO, D. E.; FILHO, F. S. O.; LIMA, F. V. S. Desenvolvimento inicial de mudas de cajueiro irrigadas com diferentes tipos de águas. Braz. Ap. Sci. Rev., Curitiba, v. 2, n. 2, p. 644-656, 2018.

PES, L. Z.; ARENHARDT, M. H. Fisiologia Vegetal. Santa Maria - RS: Universidade Federal de Santa Maria, Colégio Politécnico, Rede e-Tec Brasil, 2015.

PINTO, A. C. DE Q.; SILVA, E. M. A cultura da graviola. Empresa Brasileira de Pesquisa Agropecuária (EMBRAPA). 1995 (Coleção Plantar, 31).

PUSHARD, T. S., The State of Rainwater Harvesting In The U.S. On Tap , pp. 20-22, 2008.

SÁ, F. V. S.; BRITO, M. E. B.; MELO, P. A.; FERNANDES, P. D.; FERREIRA, I. B. Produção de mudas de mamoeiro irrigadas com água salina. Revista Brasileira de Engenharia Agrícola e Ambiental. v.17, n.10, p. 1047-1054, 2013.

SÁ, F. V. S.; BRITO, M. E. B.; FERREIRA, I. B.; ANTÔNIO NETO, P.; SILVA, L. de A.; COSTA, F. B. DA. Balanço de Sais e Crescimento Inicial de Mudas de Pinheira (Annonna squamosa L.) sob Substratos Irrigados com Água Salina. Revista Irriga. v. 20, n. 3, p. 544-556, 2015.

SOUSA, G. B.; CAVAlCANTE, L. F.; CAVALCANTE, I. H. L.; BECKMANN-CAVALCANTE, M. Z.; NASCIMENTO, J. A. Salinidade do substrato contendo biofertilizante para formação de mudas de maracujazeiro irrigado com água salina. Caatinga, v. 21, n. 2, p. 172-180, 2008.

TAIZ, L.; ZEIGER, E. Fisiologia vegetal. 5. ed. Porto Alegre: ArtMed, 2013. 954 p. 